\title{
Sociolinguistics studies of English language: analytical overview of the problem
}

\author{
N. I. Melnyk \\ National Aviation University, Foreign language philology department, Faculty of Linguistics and Social Communications, Ukraine \\ Corresponding author. E-mail: loroknataliia@gmail.com
}

Paper received 06.11.19; Accepted for publication 21.11.19.

\section{https://doi.org/10.31174/SEND-Ph2019-212VII63-09}

\begin{abstract}
The article analyzes the peculiarities the modern investigations of sociolinguistics studies of English language. The author distinguishes the main concept of this issue "sociolinguistics" and understand it as the study the language's phenomenon within the development and transformation of the society; it collates with social stratification and structure of the society; it determinates the main tendencies of language development in the connection with groups, personal, international communication. The author analyzes modern issues devoted to the sociolinguistics studies of English language. The analytical overview and theoretical investigation also allowed to distinguish the following sociolinguistics studying of English: the fist is the English language learning as the second one; the second direction is concentrated on the gender peculiarities of English language perception and learning; sociolinguistics finding in English language is the globalization; sociolinguistics studding of English language are connected with digitalization; sociolinguistics studying of English in the context of intercultural interrelations.
\end{abstract}

Keywords: English language, sociolinguistics, investigations, globalization, digitalization, interrelations.

Current investigations in linguistics cover different aspects of modern languages. The are aimed to discover peculiarities of language development in the context of world globalization [12], cultural interrelationships [10;24], computerization and digitalization all spheres of human life [25;3;2]; the scientists' interest concerns the tendencies and factors of language development $[14 ; 5 ; 6 ; 9]$; the language transformation within the sociocultural integration [15] ect. The special regard is pointed on the English as the worldwide language and as the language which as the most influenced one by different factors [2]. The very special attention in this context should be draw to sociolinguistics findings of the English.

Thus, the main goal of this issue is to analyze the modern investigations of sociolinguistics studies of English language. The aim of the article is clarified by the following tasks solving: to find out the main concept of this issue "sociolinguistics"; to analyze the main modern investigations devoted to the sociolinguistics aspects of English; to distinguish the main modern directions of sociolinguistics studies of English language.

According to Walt Wolfram language is one of the most powerful emblems of social behavior. In the normal transfer of information through language, we use language to send vital social messages about who we are, where we come from, and who we associate with. It is often shocking to realize how extensively we may judge a person's background, character, and intentions based simply upon the person's language, dialect, or, in some instances, even the choice of a single word. Given the social role of language, it stands to reason that one strand of language study should concentrate on the role of language in society. Sociolinguistics has become an increasingly important and popular field of study, as certain cultures around the world expand their communication base and intergroup and interpersonal relations take on escalating significance [18].

According to the other resources, the socio-linguistics is a fascinating and challenging field of linguistics. It studies the ways in which language interacts with society. It is the study of the way in which the structure of a language changes in response to its different social functions, and the definition of what these functions are. 'Society, here is to cover a spectrum of phenomena to do with race, nationality, more restricted regional, social and political groups, and the interac- tions of individuals within groups. Different labels have sometimes been suggested to cover various parts of this spectrum. ETHNOLINGUISTICS is sometimes distinguished from the rest, referring to the linguistic correlates and problems of ethnic groups - illustrated at a practical level by the linguistic consequences of immigration; there is a language side to race relations. The term ANTHROPOLOGICAL LINGUISTICS is sometimes distinguished from 'sociological linguistics', depending on one's particular views as to the validity or otherwise of a distinction between anthropology and sociology in the first place (for example, the former studying primitive cultures, the latter studying more 'advanced' political units; but this distinction is not maintained by many others). 'Stylistics' is another label which is sometimes distinguished, referring to the study of the distinctive linguistic characteristics of smaller social groupings. But more usually, stylistics refers to the study of the literary expression of a community using language. Socio linguistics gradually merges into ethno-linguistics, anthropological linguistics, stylistics and the subject-matter of psychology. Broadly speaking, however, the study of language as part of culture and society has now commonly been accepted as Sociolingustics. But there are also some other expressions which have been used at one time or another, including 'the sociology of language', 'social linguistics', 'institutional linguistics', 'anotheropological linguistics', 'linguistic anthropology', 'ethnolinguistics', the 'ethnography of communication', etc [17].

The group of scientists R. Satria, Ramah A. Wahab, R.Parmatasari, investigating the term Sociolinguistics, have mentioned in their study, that like its elder sisters, psycholinguistics and ethnolinguistics, it is fairly difficult to define with precision. These three fields are not different from each other entirely. In fact there is an overlap between the three. The subject matter of these three terms overlaps to a great extent. What distinguishes the three is not the material but the interests and approaches of the investigators. It is appropriate to say that sociolinguistic studies, like those carried out under the name sociology of language were pertaining to the relationship between society and language. But such a statement has excessive vagueness in it. If we try to be more exact, we may find without any ambiguity that sociolinguistics as a field of studying the relationship between language and 
society has come a long way. There has been as shift in the approach and the earlier attempts of ascertaining the language-society relationship are different from what they are today. The modern approach views language and society as structured, not a random collection of items. The sociolinguist's job is then to show the systematic covariance of social structure and linguistic structure and perhaps even to show a casual relationship in one direction or the other. However, although sociolinguists derive much of their approach from structural linguistics, at the same time they break sharply with one linguistic trend. This is the approach which treated languages as completely uniform, homogeneous or monolithic in their structure; in this view, now coming to be recognized as a pernicious one, differences in speech habits found within a community were swept under the rug as free variation'. One of the major tasks of sociolinguistics is to show that such variation or diversity is not in fact three', but is correlated with systematic social differences. In this and in still larger ways, linguistic diversity is precisely the subject matter of sociolinguistics [16].

The analysis of the issues allows to formulate the following conclusions about the term "sociolinguistics": our understanding of the sociolinguistics lies in the interrelations of the language and the society dimension, it studies the language's phenomenon within the development and transformation of the society; it collates with social stratification and structure of the society; it determinates the main tendencies of language development in the connection with groups, personal, international communication.

As for the English language sociolinguistics finding, we should point out the modern investigations on this point. This will help us to understand what is the main directions have been chosen by scientist, what social factors influence the language development.

Many research studies examining attitudes in foreign language education have been conducted at every age and proficiency level. The general aim of this line of research is to understand how students' and teachers' positive or negative attitudes towards a language influence the teaching and learning of the language. To carry out research on language attitudes, researchers have to develop a valid and reliable questionnaire incorporating psychological, sociological, and linguistic dimensions and then collect data by means of this tool. For instance, students' attitudes towards the foreign language taught will either facilitate or complicate their language learning. Study of the relationship between attitudes and learning will contribute to the development of foreign language teaching methods and materials appropriate for specific student groups exhibiting specific attitudes. At present, there are many studies of students' attitudes towards the foreign language they are learning, German, Turkish, English, and more [1]. This issue helps us to point out, that English language learning as the second is one of the main direction of sociolinguistics finding of English.

According to D. Crystal, English is the language that has spread throughout the world most extensively and is dominating in a number of important fields including international commerce, education, and communication [2]. Many countries have included English in the school curriculum in recognition that "it can contribute to students' personal, linguistic, social, and cultural development. For example, in many post-colonial countries such as India and the Philippines, English was chosen as one of the official languages and is still effectively functioning as a dominant language. Moreover, the countries which had once opposed foreign influence such as Korea, Japan, and China are now giving English language teaching and learning much greater priority in their foreign language policy [23].

Researches in language learning claim that the children who starts learning English soon, they can learn better. It certainly seems to make sense that the earlier you start, the longer you will have to learn, and the more progress you will make compared with someone who started later. However, there is evidence that this is not the case, particularly if the second language comes to take the place of the first language, which has never been allowed to develop properly. Some others claim that age is not detrimental to language learning and people of any age can be accomplished language learners [20]. Thus, the fist direction is devoted to different aspects of English language studying as a foreign language, peculiarities of English functioning in the world and sociocultural effects.

A lot of researches have investigated on the role of gender. Gender is not something we are born with, and not something we have, but something we do [7] -something we perform [Butler, J. (1990). Gender Trouble: Feminism and the Subversion of Identity. London: Routledge.]. Sex is a biological categorization based primarily on reproductive potential, whereas gender is the social elaboration of biological sex. Gender builds on biological sex and it exaggerates biological difference. People tend to consider gender as a natural phenomenon -as social and thus fluid -while sex is basically given by biology [8].This scientific researches revealed that there are natural and biological differences between girls and boys which have an effect on their learning [8]. It is largely contended that biological differences between males and females determine gender by causing enduring differences in competencies, aptitudes, and personalities. For instance, left-brain style dominance is assumed to lead men to be more "rational" and more "logical" while their relative lack of brain lateralization should lead women to be more "emotional". There is considerable argument among researchers about the linguistic styles of men and women and about the degree to which the boys and girls are treated differently by adults, and some scholars state that the similarities far outweigh the differences [19]. The second direction is concentrated on the gender peculiarities of English language perception and learning.

The following aspect of sociolinguistics finding in English language is the globalization, which interconnects people in all domains of contemporary life around the world. The issues of social and technical interdependence among the countries are resolved by implementing Globalization. There is a need for improved communication among countries to enhance these interconnections. English is the prominently used language in almost every field of study. It is used as an international language for communication in many countries and so it could be used as the global language too. As English is treated as the international language, the expansion of globalization among the countries demands evolving standardized curriculum for teaching and learning of English language. In order to meet global requirement, the individual have to acquire the global competences. Therefore, the English language curriculum must incorporate the identified global competence framework, while framing the national curriculum for languages [22]. 
The investigation of has shown, that the growth of the English language worldwide is something of a selfpropelling machine. As Short et al. have phrased it, "while the forces of cultural globalization strengthen the importance of English competency, growing global English competency accelerates the rate of cultural globalization by facilitating the movement of ideas and information." More importantly, the preeminence of the English language has been established through economic and political power. This means that for all their good intentions, invented languages like Esperanto, which are not tied to any one power-base, are unlikely to gain much momentum. It also means that in an age of ever-shifting changes, described by Zygmunt Bauman as liquid modernity, current power structures and the languages they now privilege are unlikely to remain solid for long. This certainly does not mean that the worldwide rise of English has not produced some major challenges for the world to mitigate. Although Westernization is by no means fundamentally necessary for the modernization of the developing world, the situation still stands that when such countries seek global interconnected-ness for their development, Western (or specifically American) cultural ideals often come along as side effects (often through languages like English). As evidenced in the case studies, fears of growing inequality and cultural degradation (the causes of which extend far beyond language politics) are of relevance in China, the EU, and around the world. Attempts to address these issues speak to the basic conflict between the freedom of markets and protectionist measures [13].

One more trends in sociolinguistics studding of English language are connected with digitalization. The issues of leading investigators discuss the historical changes and modern features. Events in the more recent history of the UK have had significant influence on the vocabulary of English. These events include the industrial revolution, which necessitated the coining of new words for things, and ideas that had not previously existed, and the British Empire. At its height, the empire covered one quarter of the earth's surface, and a large number of foreign words from the different countries entered the language. An increased spread of public education increased literacy, and, combined with the spread of public libraries in the19th century, books (and therefore a standard language)were exposed to a far greater number of people. Emigration of large numbers of people from many different countries to the United States of America also affected the development of American English.

The two world wars of the 20th century caused people from different backgrounds to be thrown together, and the increased social mobility that followed contributed to many regional differences in the language being lost, at least in the UK. With the introduction of radio broadcasting, and later of film and television, people were further exposed to unfamiliar accents and vocabulary, which also influenced the development of the language. Today, American English has a particularly strong influence on the development of British English, due to the USA's dominance in cinema, television, popular music, trade and technology (including the Internet). Thee growing importance of the Internet is critical for language technology in two ways. On the one hand, the large amount of digitally available language data represents a rich source for analyzing the usage of natural language, in particular by collecting statistical information. On the other hand, the Internet offers a wide range of application areas that can be improved through the use of language technology. It is an expressed political aim in the UK and other European countries to ensure equal opportunities for everyone. In particular, the Disability Discrimination Act, which came into force in 1995, together with the more recent Equality Act of 2010, have made it a legal requirement for companies and organizations to ensure that their services and information are accessible to all. This requirement applies directly to websites and Inter-net services. User-friendly language technology tools offer the principal solution to satisfy this legal regulation, for example, by offering speech synthesis for the blind. Internet users and providers of web content can also profit from language technology in less obvious ways, e. g., in the automatic translation of web contents from one language into another. Considering the high costs associated with manually translating these contents, it may be surprising how little usable language technology is built-in, compared to the anticipated need. However, it becomes less surprising if we consider the complexity of the English language, which has been partially high-lighted above, and the number of technologies involved in typical language technology applications. [21, P. 10-14].

One of the trends is the sociolinguistics studying of English in the context of intercultural interrelations. The last investigations say that the 'intercultural dimension' in language teaching aims to develop learners as intercultural speakers or mediators who are able to engage with complexity and multiple identities and to avoid the stereotyping which accompanies perceiving someone through a single identity. It is based on perceiving the interlocutor as an individual whose qualities are to be discovered, rather than as a representative of an externally ascribed identity. Intercultural communication is communication on the basis of respect for individuals and equality of human rights as the democratic basis for social interaction. So language teaching with an intercultural dimension continues to help learners to acquire the linguistic competence needed to communicate in speaking or writing, to formulate what they want to say/write in correct and appropriate ways. But it also develops their intercultural competence i.e. their ability to ensure a shared understanding by people of different social identities, and their ability to interact with people as complex human beings with multiple identities and their own individuality. Social identities are related to cultures. Someone who is 'Chinese' will have acquired that identity through being brought up surrounded by other Chinese, unconsciously learning their beliefs, values and behaviours. Similarly someone whose social identities include being 'a teacher' will have acquired the knowledge, values and behaviours they share with other teachers through a process of socialization. But this is still a simplification because Chinese and teachers have many other identities and every individual and there are many different ways of being Chinese or a teacher. So to see only one identity in a person is a simplification. An intercultural speaker is aware of this simplification, knows something about the beliefs, values and behaviours, which are 'Chinese', but is also aware that there are other identities hidden in the person with whom they are interacting, even if they do not know what the associated beliefs, values and behaviours are. Therefore, an intercultural speaker needs some knowledge, about what it means to be Chinese or a teacher or indeed a Chinese teacher, for example. However, an intercultural speaker also needs an awareness that there is more to be 
known and understood from the other person's perspective, that there are skills, attitudes and values involved too (see following section), which are crucial to understanding intercultural human relationships. As a consequence, the 'best' teacher is neither the native nor the non-native speaker, but the person who can help learners see relationships between their own and other cultures, can help them acquire interest in and curiosity about 'otherness', and an awareness of themselves and their own cultures seen from other people's perspectives. [4, p. 10 ]. This proves, that developing the intercultural dimension in language teaching involves recognizing that the aims are: to give learners intercultural competence as well as linguistic competence; to prepare them for interaction with people of other cultures; to enable them to understand and accept people from other cultures as individuals with other distinctive perspectives, values and behaviours; and to help them to see that such interaction is an enriching experience.

Conclusion. The scientific analysis of the modern issues devoted to the sociolinguistics studying of English language made it possible to formulate our understanding of the sociolinguistics, which lies in the interrelations of the language and the society dimension and according to which sociolinguistics studies the language's phenomenon within the development and transformation of the society; it collates with social stratification and structure of the society; it determinates the main tendencies of language development in the connection with groups, personal, international communication. The analytical overview and theoretical investigation also allowed to distinguish the following sociolinguistics studying of English: the fist is the English language learning as the second one; the second direction is concentrated on the gender peculiarities of English language perception and learning; sociolinguistics finding in English language is the globalization; sociolinguistics studding of English language are connected with digitalization; sociolinguistics studying of English in the context of intercultural interrelations. The presented issue doesn't exclude all aspect of the sociolinguistics investigation of English language the further researchers should be done in the investigating of national identification in English language, the scientific interest concerns also Ethnic representation in English language, what is going to be the subject of the our further researches.

\section{REFERENCES}

1. Bayyurt, Y.,The Journal of Language Teaching and Learning, 2013-1, 53-78.

2. Crystal, D. (1997). English as a global language. Cambridge: Cambridge University Press.

3. Darvin, Ron. (2016). Language and identity in the digital age.; The Routledge Handbook of Language and Identity, Chapter: 33, pp.523-540; David Crystal. Evoling English: One Language, Many Voices. The British Library Publishing Division, 2010.

4. DEVELOPING THE INTERCULTURAL DIMENSION IN LANGUAGE TEACHINGA PRACTICAL INTRODUCTION FOR TEACHERSMichael BYRAM, Bella GRIBKOVA and Hugh STARKEY https://rm.coe.int/16802fc1c3

5. Ellis, R. (1985). Understanding second language acquisition. Oxford: Oxford University Press.

6. Fishman, J. A., Rubal-Lopez, A., \& Conrad, A. W. (Eds.) (1996). Post-imperial English. Berlin: Mouton de Gruyter; Greenbaum, S. (1996). Afterword. In R. J. Baumgardner (Ed.), South Asian English: Structure, use and users (pp. 239-245). Urbana, IL: The University of Illinois Press

7. Gleason, J. (1987). Sex differences in parent-child interaction. In Susan Philips, Susan Steele, and Christine Tanz (eds) Language, Gender and Sex in Comparative Perspective. Cambridge: Cambridge UniversityPress.

8. Gurian, M., Henley, P., \& Trueman, T. (2001). Boys and girls learn differently: A guide for teachers and parents. San Francisco: Jossey-Bass.

9. Hargreaves, A., \& Fullan, M. G. (Eds.). (1992). Understanding teacher development. New York: Teachers College Press.

10. Ingrid Madárová, Mgr. Roman Čančinov. Aspects of interrelationship between culture and language in the context of second/foreign language acquisition. Oxford University Press, Budovatel'ská 63/A, $080 \quad 01 \quad$ Prešov, Slovakia. https://exclusiveejournal.sk/files/1-2015/1-madarova.pdf

11. Johnson, Anne (2009) "The Rise of English: The Language of Globalization in China... Available at: http://digitalcommons.macalester.edu/macintl/vol22/iss1/12... Macalester International Vol. 22.

12. Johnson, Anne (2009) "The Rise of English: The Language of Globalization in China and the European Union,"MacalesterInternational: Vol. 22, Article 12. Available at:http://digitalcommons.macalester.edu/macint1/vol22/iss1/12

13. Joshua A. Fishman, “The New Linguistic Order," Foreign Policy 113 (1999): 37.

14. Kawabata, T. (2006). The use of computer-assisted language learning for literacy development. Retrieved January 19, 2008, from http://www.eltnews.com/features/

15. Service, E.1968: Origins of the State and Civilizations; Norton, New York.; Neuman, W. L.1997: Social Research Methods: Qualitative and Quantitative Approaches. Allyn and Bacon, Needham Heights.

16. Sociolinguistic relationship between language and society. R. Satria, Ramah A. Wahab, R.Parmatasari. assignment of Mr. Sholihin M.Hum. https://www.academia.edu/10218217/Relation_between_languag e_and_society

17. SocioLinguistics - A Study of Language and Societhttps://neoenglish.wordpress.com/2010/12/26/sociolin guistics-a-study-of-language-and-society/

18. Sociolinguistics.Linguistic Society of America https://www.ling uisticsociety.org/resource/sociolinguistics

19. Tannen, D. (1990). You Just Don't Understand: Women and Men in Conversation. New York: WilliamMorrow

20. The Effects Of sociolinguistics factors on learning English: A Case Study. http://www.ijllt.org/wp-content/uploads/2019/03/20The-Effects-Of-sociolinguistics-factors-on-learning-English-ACase-Study.pdf

21. THE ENGLISHLANGUAGE INTHE DIGITALAGE. Sophia Ananiadou, John McNaught, Paul Thompson. THE META-NET WHITE PAPER SERIES. http://www.metanet.eu/whitepapers/e-book/english.pdf

22. Thiruvengadam, Pushpanathan. (2013). English Language in the Context of Globalization. 10.13140/RG.2.1.2487.1447

23. Tsui, A. B. M. (2004). Language policies in Asian countries: Issues and tensions. The Journal of Asia TEFL, 1, 1-25.

24. Valdes, Joyce Merrill. 1986.Language, thought, and culture. [aut.] Nelson Brooks. Culture Bound. Cambridge Language Teaching Library. Cambridge: Cambridge University Press, 1986, 12, s. 1

25. Yaman, İsmail. (2015). Digital Divide within the Context of Language and Foreign Language Teaching. Procedia - Social and $\begin{array}{llll}\text { Behavioral } & \text { Sciences. } & \text { 766-771. }\end{array}$ 10.1016/j.sbspro.2015.01.538. 